\title{
Dynamic Response Of Laminated Composite Shells Subjected To Impulsive Loads
}

\author{
Arafa El-Helloty \\ Associated Professor of Structures, Department of Civil Engineering, Al-Azhar University, Egypt
}

\begin{abstract}
Laminated composite shells are widely used in the aerospace, civil, marine, and automotive industries due to their high strength and stiffness to weight ratios, outstanding bending rigidity, excellent vibration characteristics and many other superior properties compared to ordinary shells. In this paper, the effect of number of layers, orientation angle and boundary conditions on the dynamic response of laminated composite shells subjected to impulsive loads is examined using the finite element system ANSYS16. Arc shells are used with two types of boundary conditions which are simply and fixed supported. The results are plotted in time history graphs for total displacement and equivalent stresses and it are discussed.
\end{abstract}

Keywords: Laminated, composite shell, cross-ply, angle-ply, number of layers, symmetric arrangement, transient dynamic analysis

\section{Introduction}

Laminated composite materials are increasingly used in structural design such as buildings, aerospace, transportation, novel and pressure vessels due to their merits such as low density, high stiffness and high strengths as compared with traditional materials. Apart from having high specific stiffness and strength values, composite materials offer great potential for tailoring structural design for weight saving and desirable mechanical behaviour against applied loads. Shell structures constitute a major component of structural elements such as the roofs of buildings, storage tanks, aircraft, spacecraft, rockets, cars, computers, submarines and boats. Laminated composite shells are extensively used in many fields of modern engineering practices which it are required high strength-weight and stiffness-weight ratios and they are subjected to various static and dynamic loading. Among the most common types of loading, shells may be subjected to external pulse loads such as explosions or blast loads which it are not only challenge the strength of the structure but it also lead to loss of stability and collapse of the whole structure.

In the literature, studies have been presented on investigating the behavior of laminated composite shells subjected to dynamic loading. However, studies on the response of laminated composite shells subjected to impulsive loads are limited. S. K. Sahu and P. K. Datta [1] investigated the dynamic stability of laminated composite curved panels with cutouts subjected to in-plane static and periodic compressive loads using the finite element method. The effects of size of cutout, ply orientation, static and dynamic load factors, curvature, geometry, and various boundary conditions on the instability behaviour of laminated composite curved panels with cutouts were carried out. A. Karmakara and K. Kishimotob, [2] studied the response of delaminated composite pre-twisted rotating shallow shells subjected to low velocity impact using the finite element method. The investigation was carried out for moderate rotational speeds and parametric studies were performed in respect of location of delaminated, angle of twist and rotational speed for graphite/epoxy composite cylindrical shells. A. L. Poore, et al. [3] presented a semi-analytical solution method for determining the natural frequencies and mode shapes of laminated composite cylindrical shells containing a circular cutout. The effects of a cutout on the natural frequencies and mode shapes were investigated for increasing cutout size, shell radius, and shell thickness. Also, the effect of the ply layup and the boundary conditions on the natural frequencies and mode shapes of cylindrical laminated composite shells were demonstrated. S. Kumar, [4] presented a nonlinear finite element transient dynamic analysis to predict the impact response and the impact-induced damage in a laminated composite cylindrical shell subjected to transverse impact. Example problems of graphite/epoxy cylindrically curved laminates with different curvature were considered and the influence of geometrical nonlinearity on the impact response and the resulting damage were demonstrated. Also, the concurrent effect of material degradation due to impact damage was investigated. F. S. d. Almeida and A. M. Awruch, [5] presented a numerical study on the dynamic analyses of laminated composite shells considering geometrically nonlinear effects. To perform the dynamic analysis, the algorithm employed for the analysis was composed by a linear composite shell element which it was associated with the element independent corotational formulation to account the geometric nonlinearity. F. Firouzabadi1 et al. [6] developed a three dimensional finite element model to examine the dynamic response of laminated composite cylindrical shell subjected to pure impact. Two important parameters in dynamic response of laminated composite cylindrical shell which were radial deflection and contact force of the contact point on cylinder surface were recorded for the whole period of the contact 
motion. A. Kumar et al. [7] examined the free vibration of laminated composite cylindrical shells with rectangular cutouts using the two dimensional finite element implementation which it was based on the higher order shear deformation theory. Free vibration analysis of laminated composite shells with cutouts was done for first five modes by varying boundary conditions and geometry of composite shells.V. Chitra and R. S. Priyadarsini [8] investigated the behavior of thin walled composite circular cylindrical shells under axial impact loading using the finite element software ABAQUS. Two composite circular cylindrical shells with different layups were considered and the approach of Budiansky-Roth criterion was adopted to calculate the buckling loads under dynamic impact conditions. R. R. Dasa, et al. [9] presented a three dimensional finite element modelling and simulation techniques to investigate the free vibration response of different laminated composite shell structures. The developed model was capable of studying the effect of different boundary conditions on the natural frequency of vibration of a spherical shell structures that made from FRP laminated composite. S. M. Saji and Prabha [10] studied the effect of modulus ratios, span-to-thickness ratios, boundary conditions and layup sequences on the vibrations response of shallow thin laminated composite shells with various shapes. Also, the effect of elastically restrained edges on various shell curvatures including spherical and cylindrical shell was examined. C. Lakshmi and K. K. Smitha, [11] investigated the free vibration behavior of laminated composite cylindrical panels using the finite element software ANSYS with arbitrary end conditions. The effects of various parameters such as radius to side ratio, side to thickness ratio and different laminates on the free vibration response of laminated composite cylindrical panels were carried out. K. S. Ram and T. V. Jyothi [12] examined the transient dynamic behavior of laminated composite spherical shell cap subjected to suddenly applied uniform normal pressure using the finite element method. Dynamic response of deflection and stress was studied for orthotropic symmetrically and anti-symmetrically laminated cross-ply spherical shell caps with simply and clamped supported.

Therefore, the aim of this paper is to study the effect of number of layers, orientation angle and boundary conditions on the dynamic response of laminated composite shells subjected to impulsive loads using the finite element system ANSYS16. Simply and fixed supported laminated composite arc shells are considered with symmetric cross and angle-ply laminates and the transient dynamic analysis is carried out.

\section{Numerical Example}

To study the effect of number of layers, orientation angle and boundary conditions on the response of laminated composite shells subjected to impulsive loads, the transient dynamic analysis of a laminated composite arc shell with cross-section $1000 \mathrm{~mm} \times 1.0 \mathrm{~mm}$ and mean radius of arc $R=1000 \mathrm{~mm}$ subjected to impulsive loads is considered as shown in Fig. 1. In this study, Laminates are composite shells consisting of four, six, eight and ten orthotropic plies of the same material and equal thickness with the overall thickness kept constant. Both cross-ply and angle-ply laminates with symmetric arrangements are considered and for angle-ply laminates, the orientation angle $\theta^{0}$ is $30^{\circ}, 45^{\circ}$ and $60^{\circ}$ respectively. Two different boundary conditions which are simply supported and fixed supported at edges A and B are considered as shown in Fig. 1. The shell is subjected to triangular impulsive loading with peak value $=1000 \mathrm{~N}$ and load duration is $0.1 \mathrm{sec}$ as shown in Fig. 1 . A Epoxy/ Carbon composite material (UD 395 Gpa Prepreg) from ANSYS composite materials library is used and the materials properties are given as $E_{1}=209 \mathrm{GPa}, E_{2}=9.45 \mathrm{GPa}, E_{3}=9.45 \mathrm{GPa}, G_{12}=5.5 \mathrm{GPa}, G_{13}=5.0 \mathrm{GPa}$, $G_{23}=3.9 \mathrm{GPa}, v_{12}=0.27, v_{13}=0.27, v_{23}=0.4$ and $\rho=1540 \mathrm{~kg} / \mathrm{m}^{3}$ for Young's modulus, shear modulus, Poisson's ratio and density respectively.
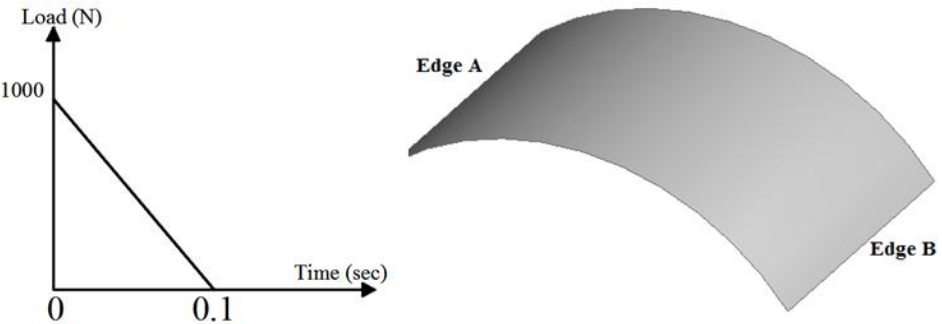

Fig. 1: Arc shell and triangular impulsive loading

\section{2-1 Method of analysis}

The transient dynamic analysis has been done by 8-node SHELL281 element in finite element system ANSYS16. The SHELL281 as shown in Fig. 2. is a eight-node element with six degrees of freedom at each node that are translations in the $\mathrm{x}, \mathrm{y}$, and $\mathrm{z}$ axes, and rotations about the $\mathrm{x}, \mathrm{y}$, and $\mathrm{z}$-axes. For transient dynamic analysis, The basic equation of motion solved by a transient dynamic analysis is: 
$[M]\{\ddot{u}\}+[C]\{\dot{u}\}+[K]\{u\}=\{F(t)\}$

Where:

$[\boldsymbol{M}]=$ mass matrix, $[\boldsymbol{C}]=$ damping matrix, $[\boldsymbol{K}]=$ stiffness matrix, $\{\boldsymbol{F}(\boldsymbol{t})\}=$ time varying load vector, $\{\bar{u}\}=$ nodal acceleration vector, $\{\dot{u}\}=$ nodal velocity vector and $\{\boldsymbol{u}\}=$ nodal displacement vector.

At any given time, $t$, these equations can be thought of as a set of static equilibrium equations that it also take into account inertia forces $[\boldsymbol{M}]\{\tilde{u}\}$ and damping forces $[\boldsymbol{C}]\{\dot{\boldsymbol{u}}\}$. The time increment between successive time points is called the integration time step and the Newmark time integration method is used to solve these equations at discrete time points. The transient dynamic analysis is done with time step integration $\Delta \mathrm{t}=0.01 \mathrm{sec}$ and end time step $=0.5 \mathrm{sec}$ and The governing equations of forced vibration are solved using the Newmark direct integration method.

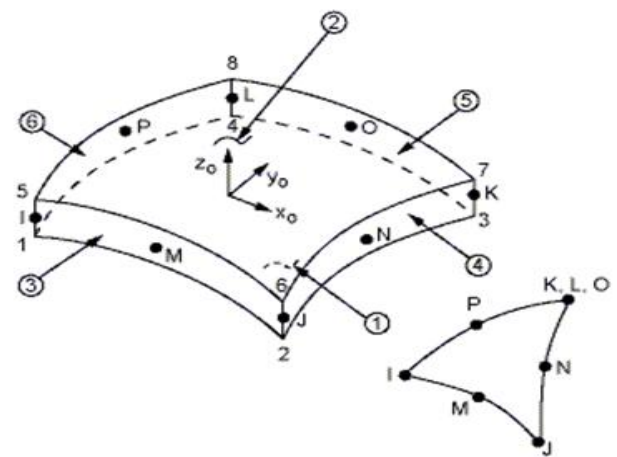

$\boldsymbol{x}_{\boldsymbol{o}}=$ Element $\mathrm{X}$-axis if element orientation is not provided

$\boldsymbol{x}=$ Element $\mathrm{x}$-axis if element orientation is provided.

Fig. 2: 8-node SHELL281 element

\section{Results And Discussion}

The transient dynamic analysis has been carried out and to study the effect of variation of number of layers, orientation angle and boundary conditions on the dynamic response of laminated composite shells, the results obtained by the transient dynamic analysis are analyzed. For simplicity, the results are presented by charts as follows:

\section{3-1 Effect of number of layers}

Fig. 3. And Fig. 4. present the total displacement and the equivalent stress distributions of simply supported shells for four layers cross-ply and sex, eight and ten layers angle-ply $30^{\circ}, 45^{\circ}$ and $60^{\circ}$ laminates respectively at time $=0.05 \mathrm{sec}$. Fig. 5. and Fig. 6. present the total displacement and the equivalent stress distributions of fixed supported shells for four layers cross-ply and sex, eight and ten layers angle-ply $30^{\circ}, 45^{\circ}$ and $60^{\circ}$ laminates respectively at time $=0.04 \mathrm{sec}$.

Fig. 7. to Fig. 10. present time-displacement response for total displacement for cross and angle-ply $30^{\circ}, 45^{\circ}$ and $60^{\circ}$ laminates of simply supported shells respectively. Fig. 11. to Fig. 14. present time-stress response for equivalent stress for cross and angle-ply $30^{\circ}, 45^{\circ}$ and $60^{\circ}$ laminates of simply supported shells respectively.

Fig. 15. to Fig. 18. present time-stress response for total displacement for cross and angle-ply $30^{\circ}$, $45^{\circ}$ and $60^{\circ}$ laminates of fixed supported shells respectively. Fig. 19. to Fig. 22. present time-stress response for equivalent stress for cross and angle-ply $30^{\circ}, 45^{\circ}$ and $60^{\circ}$ laminates of fixed supported shells respectively.

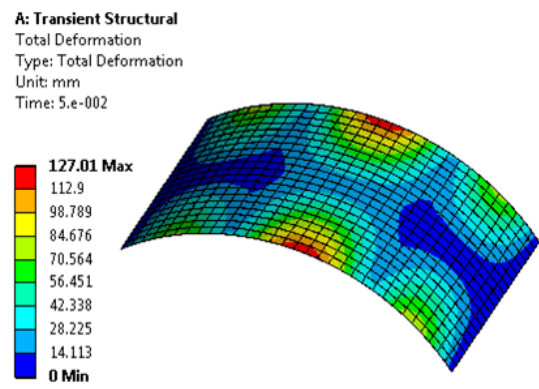

4 layers cross-ply laminates

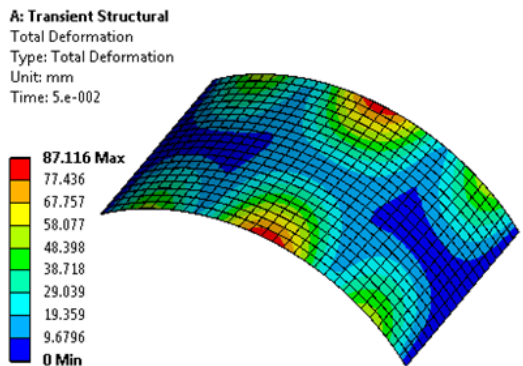

6 layers angle-ply $30^{0}$ laminates 


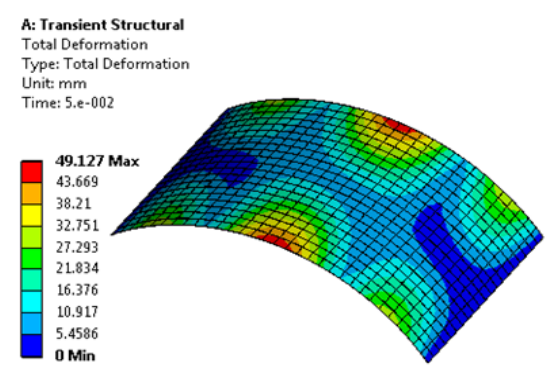

8 layers angle-ply $45^{\circ}$ laminates
A: Transient Structur

Type: Total Deformation

Unit: $\mathrm{mm}$

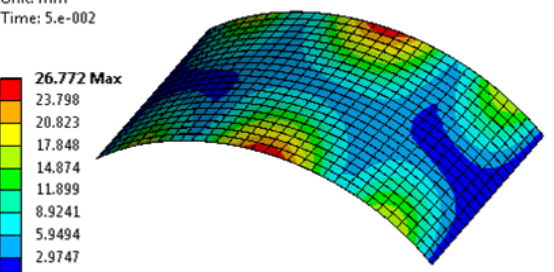

10 layers angle-ply $60^{\circ}$ laminates

Fig. 3: Total displacement distribution of simply supported shells for four layers cross-ply and six, eight and ten layers angle-ply laminates at time $0.05 \mathrm{sec}$

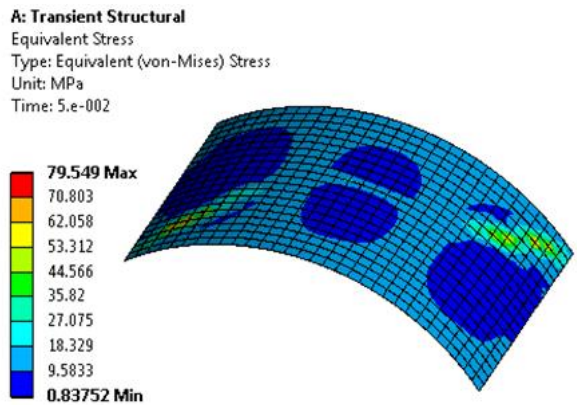

4 layers cross-ply laminates

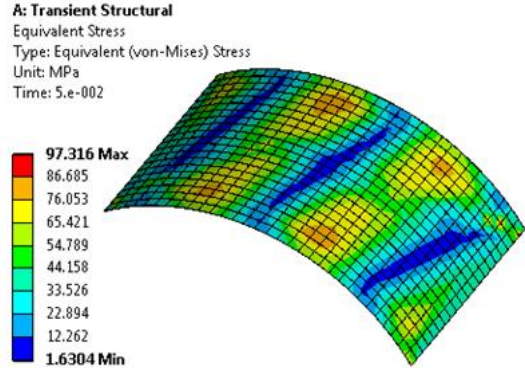

6 layers angle-ply $30^{\circ}$ laminates

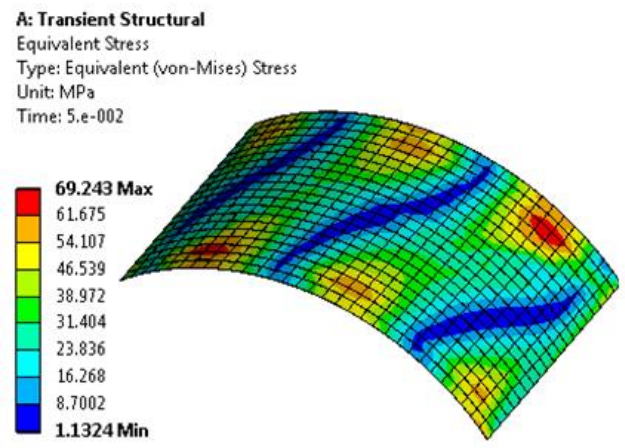

8 layers angle-ply $45^{\circ}$ laminates

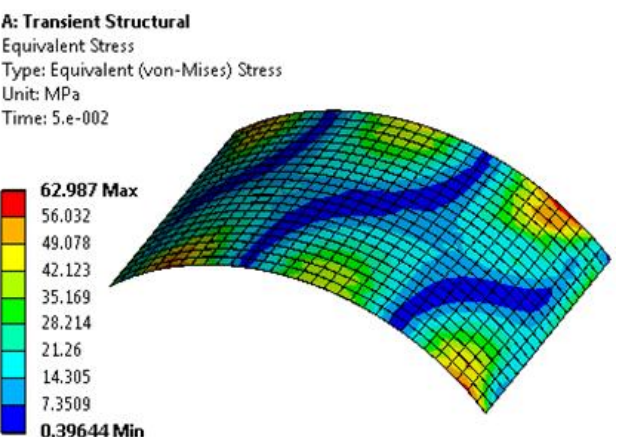

$0.39644 \mathrm{Min}$

10 layers angle-ply $60^{\circ}$ laminates

Fig. 4: Equivalent stress distribution of simply supported shells for four layers cross-ply and six, eight and ten layers angle-ply laminates at time $0.05 \mathrm{sec}$

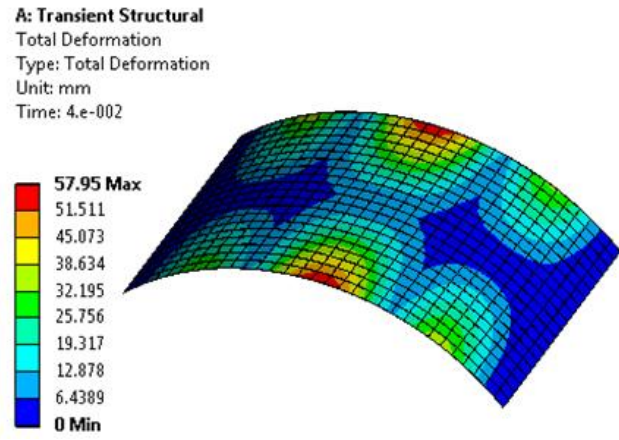

4 layers cross-ply laminates

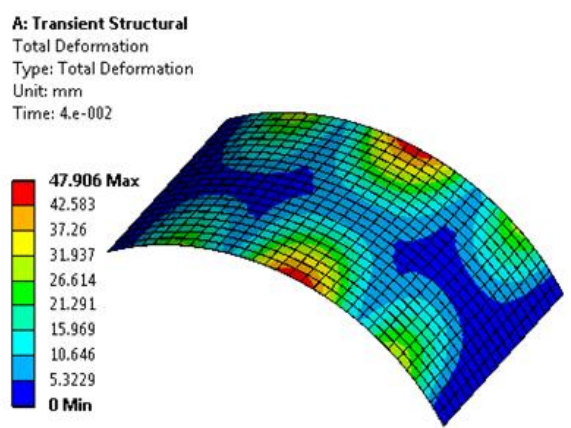

6 layers angle-ply $30^{\circ}$ laminates 


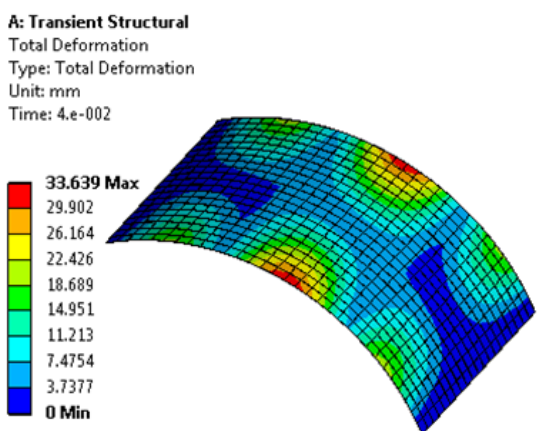

8 layers angle-ply $45^{\circ}$ laminates

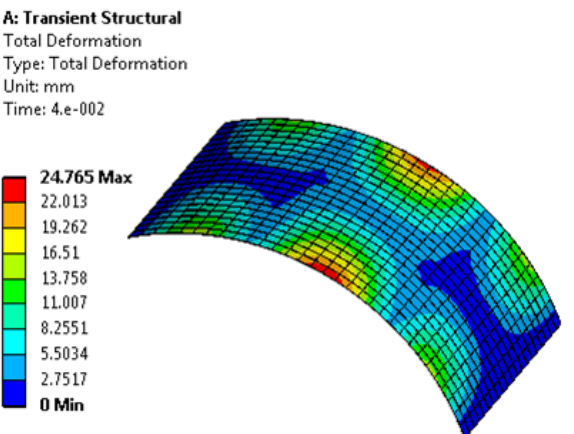

10 layers angle-ply $60^{\circ}$ laminates

Fig. 5: Total displacement distribution of fixed supported shells for four layers cross-ply and six, eight and ten layers angle-ply laminates at time $0.04 \mathrm{sec}$

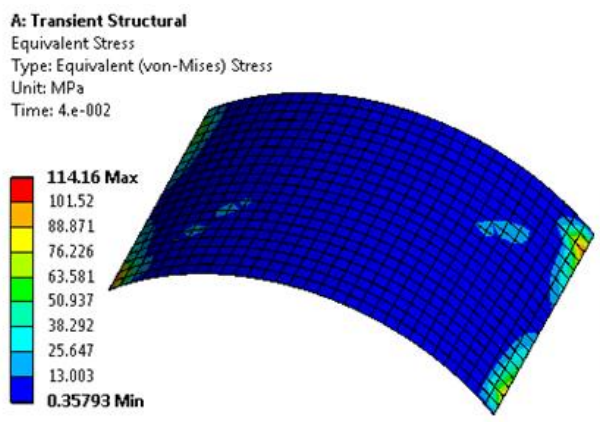

4 layers cross-ply laminates

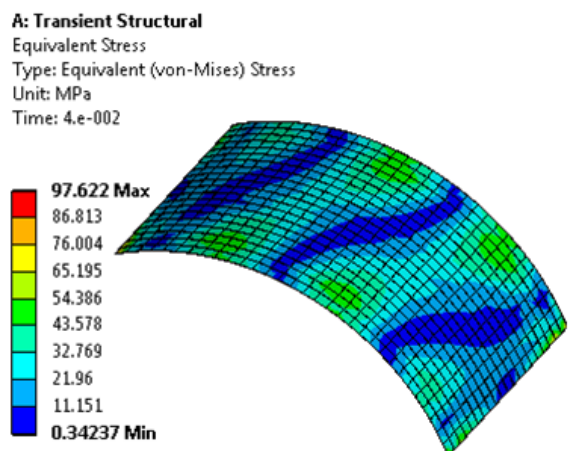

8 layers angle-ply $45^{0}$ laminates

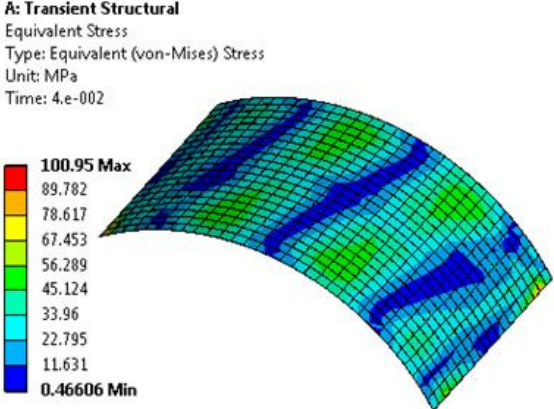

6 layers angle-ply $30^{\circ}$ laminates

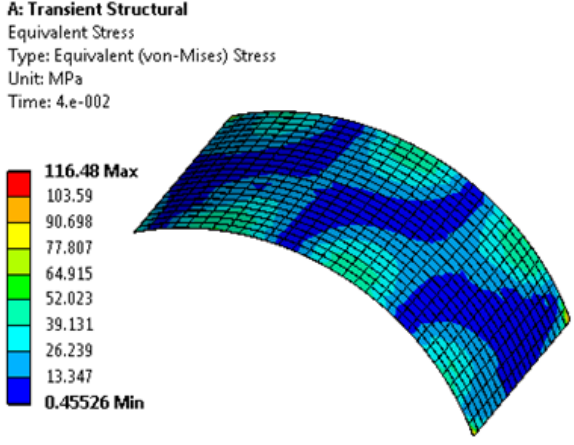

10 layers angle-ply $60^{\circ}$ laminates

Fig. 6: Equivalent stress distribution of fixed supported shells for four layers cross-ply and six, eight and ten layers angle-ply laminates at time $0.04 \mathrm{sec}$

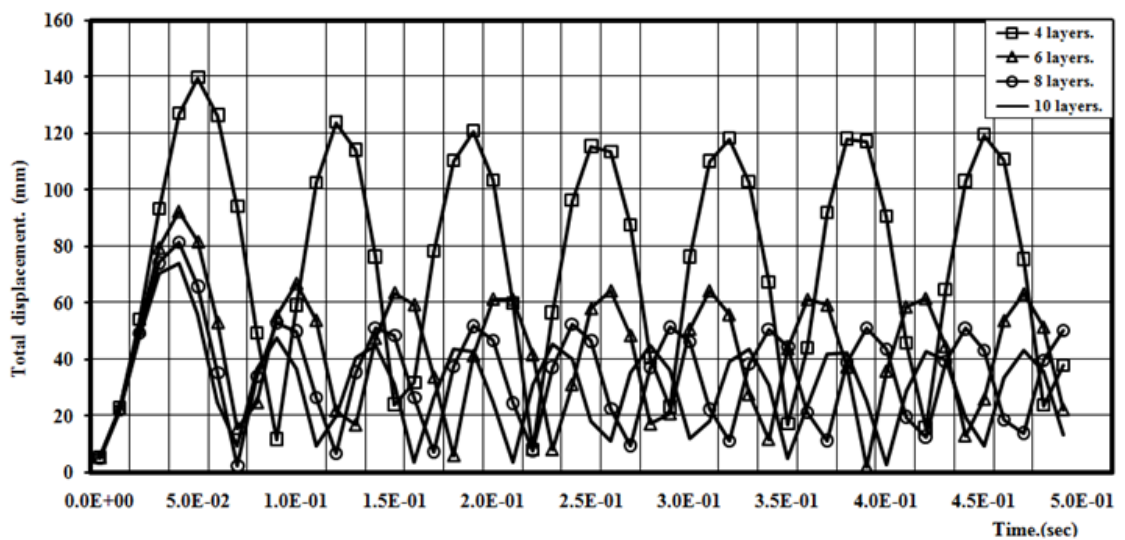

Fig. 7: Time-displacement response for total displacement for cross-ply laminates of simply supported shells 


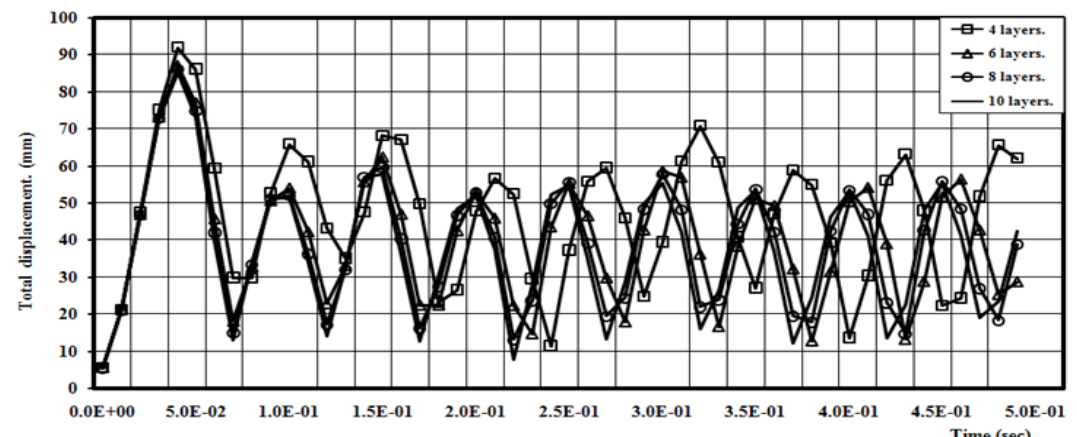

Fig. 8: Time-displacement response for total displacement for angle-ply $30^{\circ}$ laminates of simply supported shells

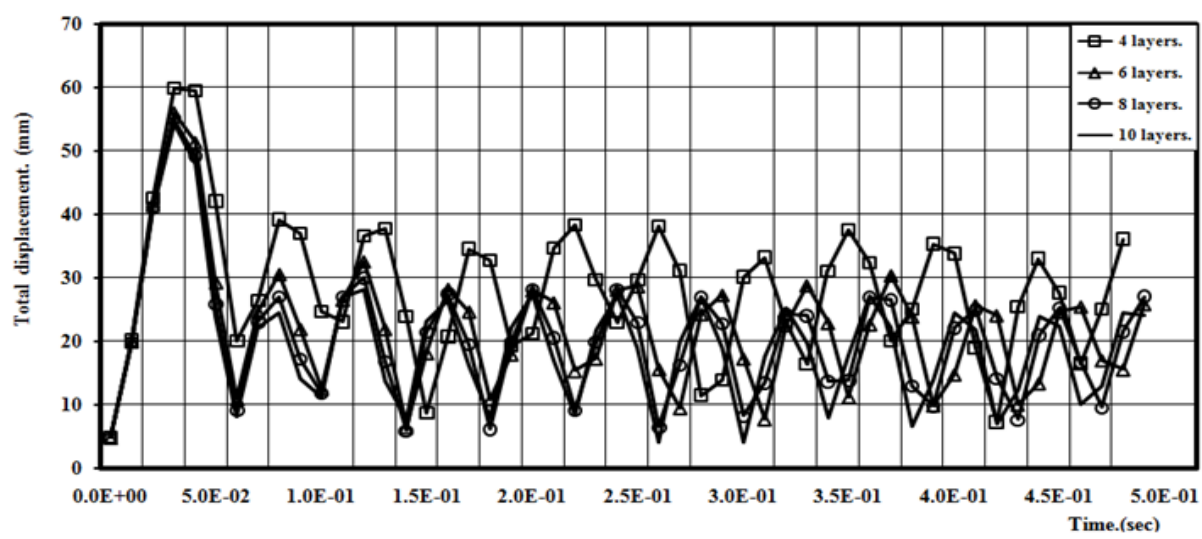

Fig. 9: Time-displacement response for total displacement for angle-ply $45^{0}$ laminates of simply supported shells

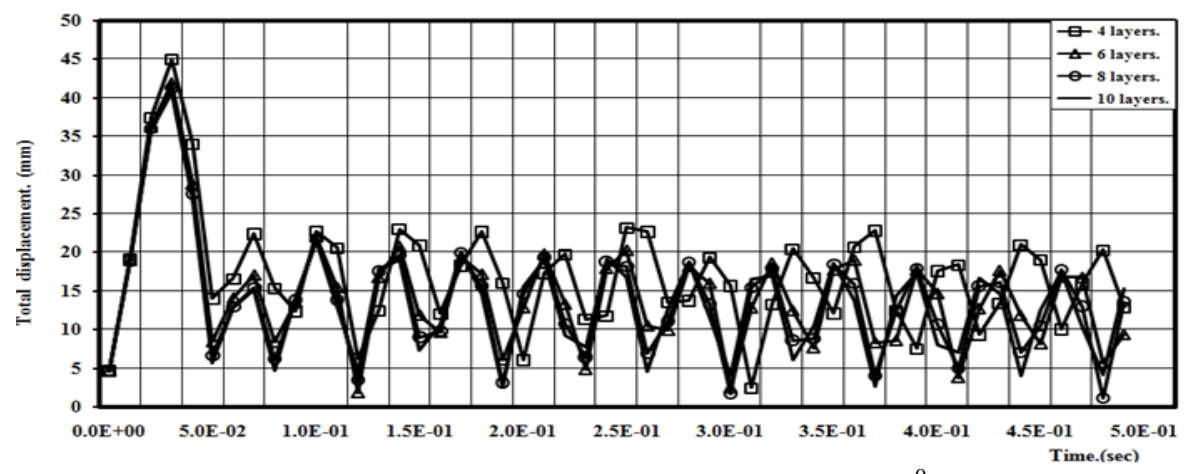

Fig. 10: Time-displacement response for total displacement for angle-ply $60^{0}$ laminates of simply supported shells

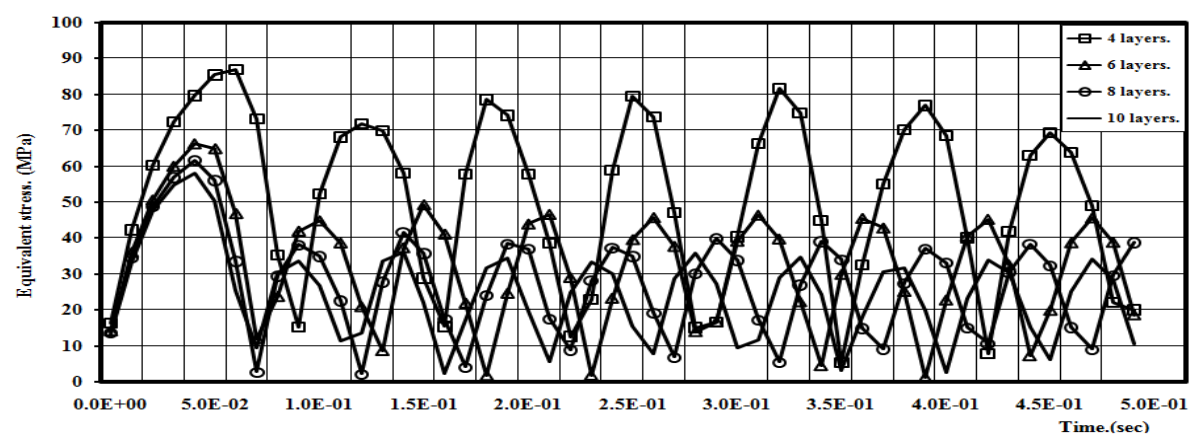

Fig. 11: Time-stress response for equivalent stress for cross-ply laminates of simply supported shells 


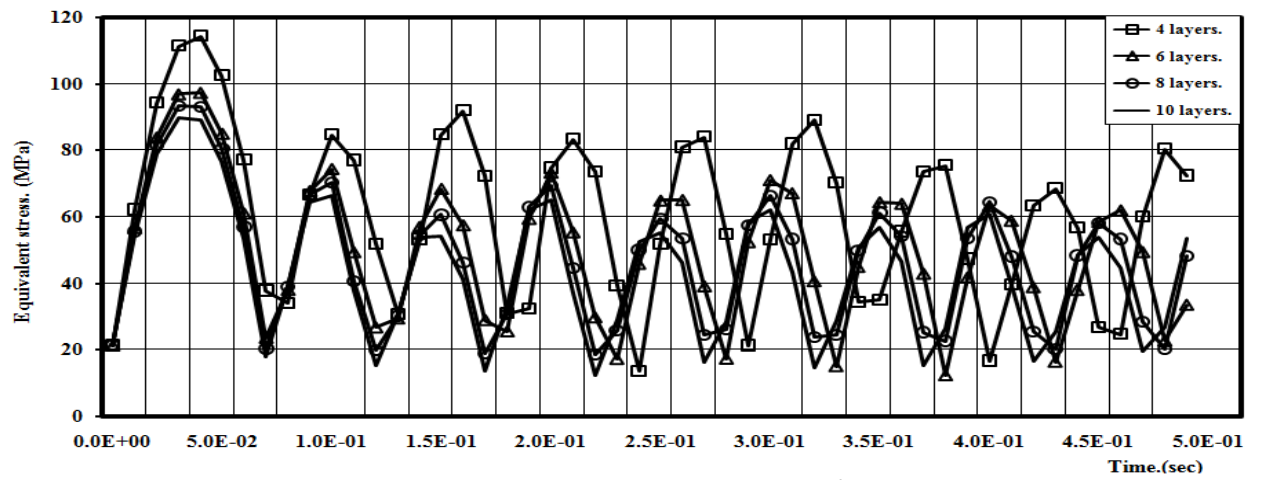

Fig. 12: Time-stress response for equivalent stress for angle-ply $30^{\circ}$ laminates of simply supported shells

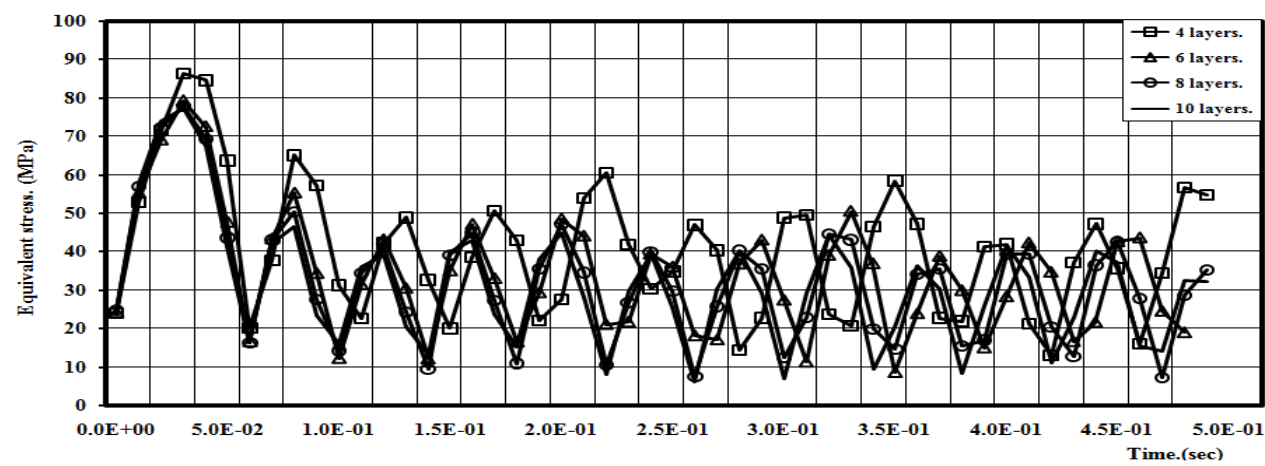

Fig. 13: Time-stress response for equivalent stress for angle-ply $45^{0}$ laminates of simply supported shells

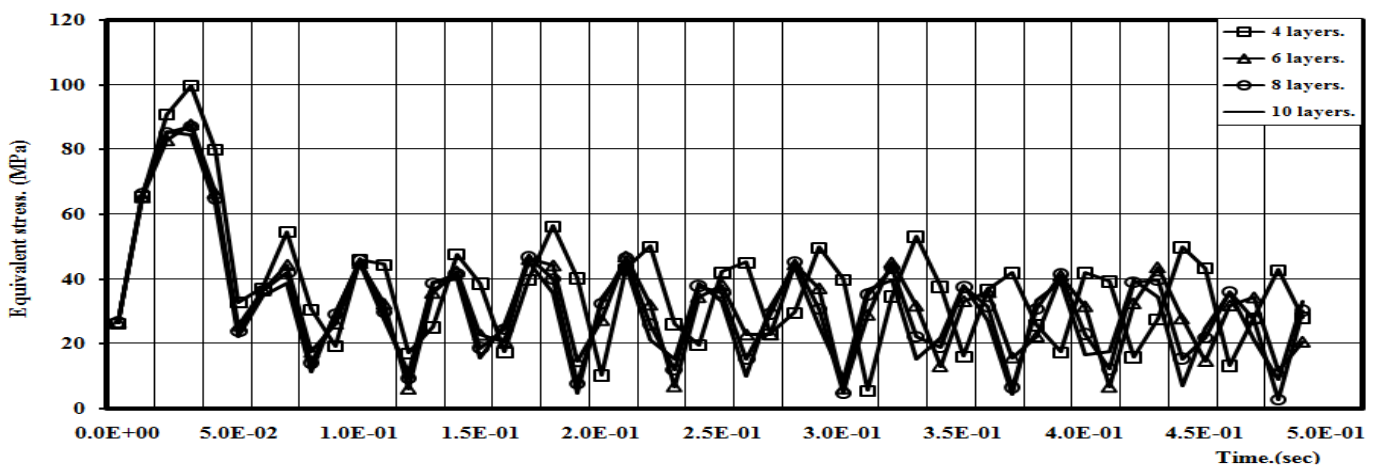

Fig. 14: Time-stress response for equivalent stress for angle-ply $60^{\circ}$ laminates of simply supported shells

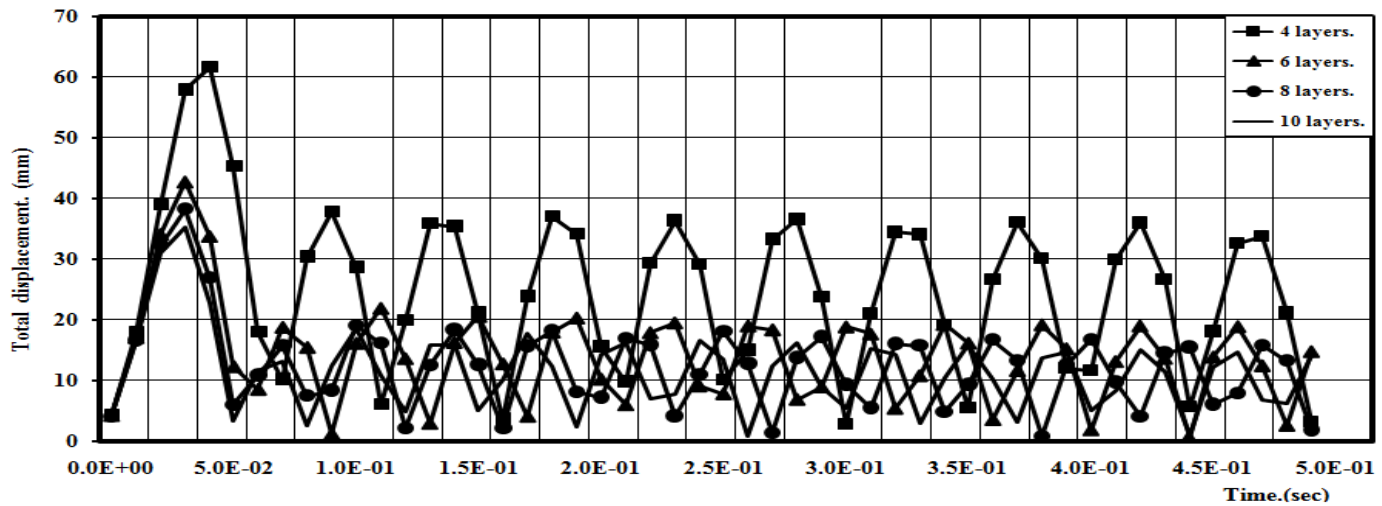

Fig. 15: Time-displacement response for total displacement for cross-ply laminates of fixed supported shells 


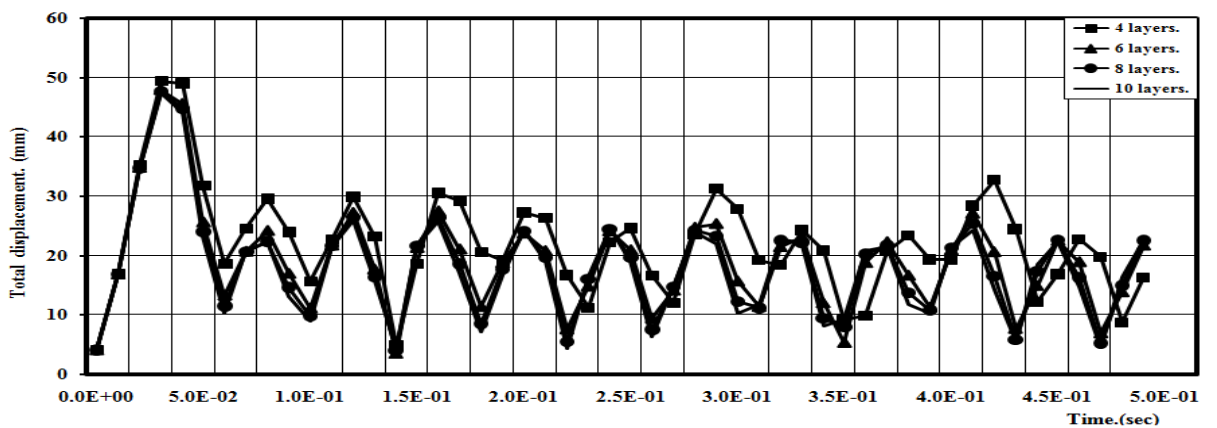

Fig. 16: Time-displacement response for total displacement for angle-ply $30^{0}$ laminates of fixed supported shells

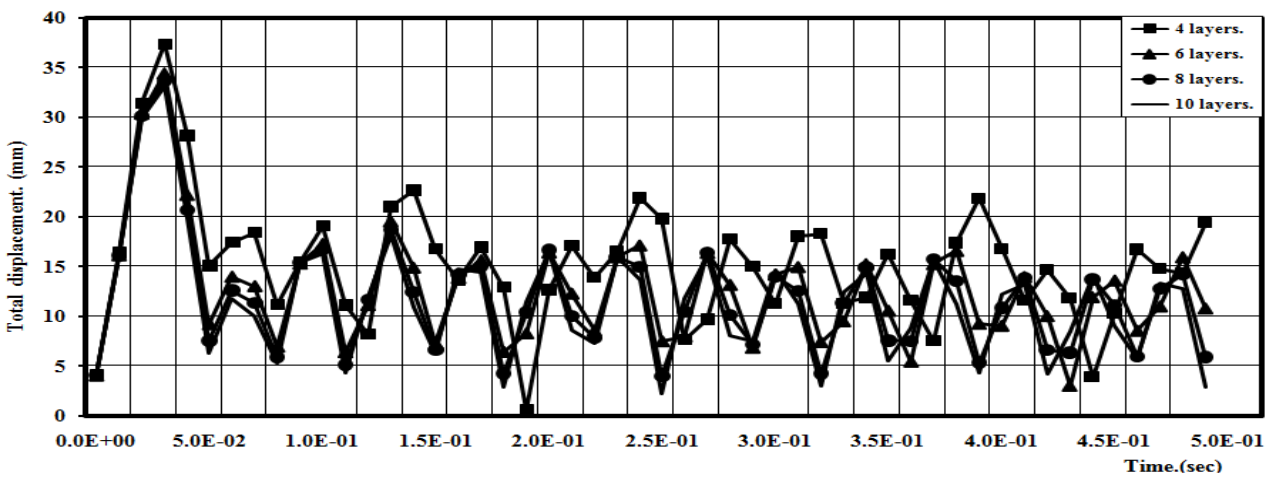

Fig. 17: Time-displacement response for total displacement for angle-ply $45^{0}$ laminates of fixed supported shells

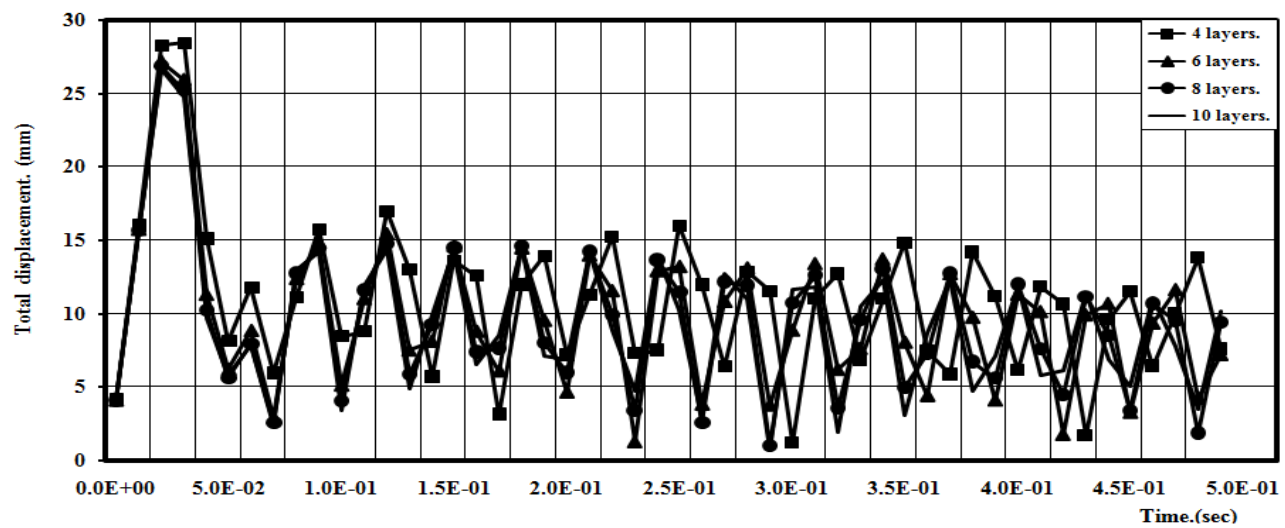

Fig. 18: Time-displacement response for total displacement for angle-ply $60^{\circ}$ laminates of fixed supported shells

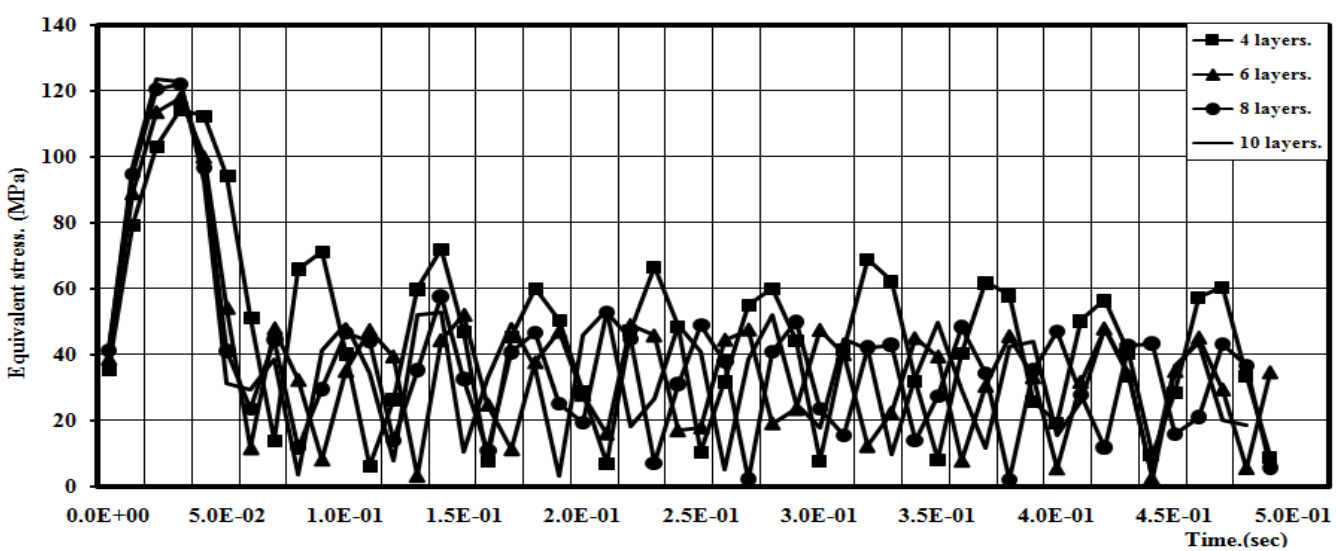

Fig. 19: Time-stress response for equivalent stress for cross-ply laminates of fixed supported shells 


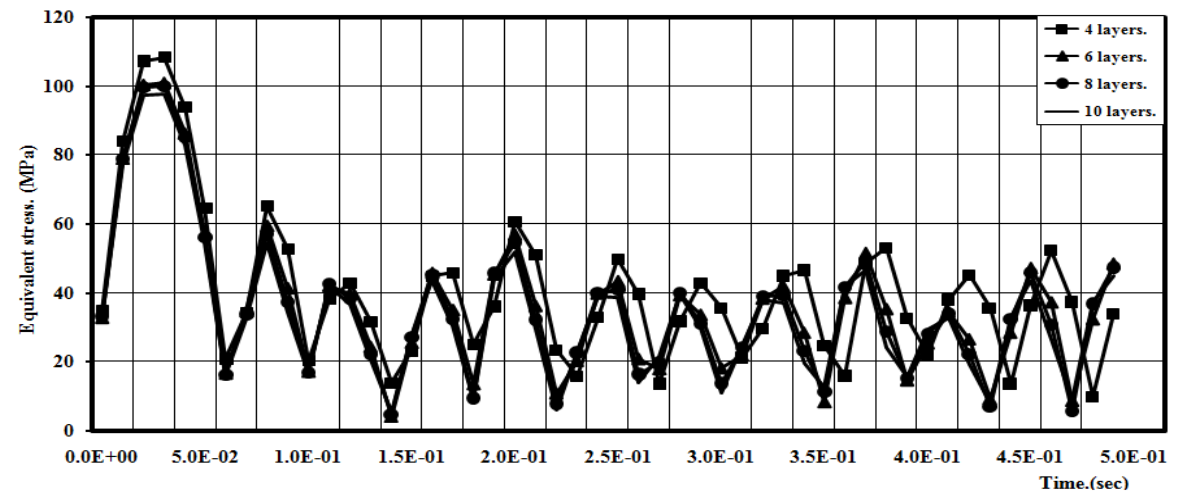

Fig. 20: Time-stress response for equivalent stress for angle-ply $30^{0}$ laminates of fixed supported shells

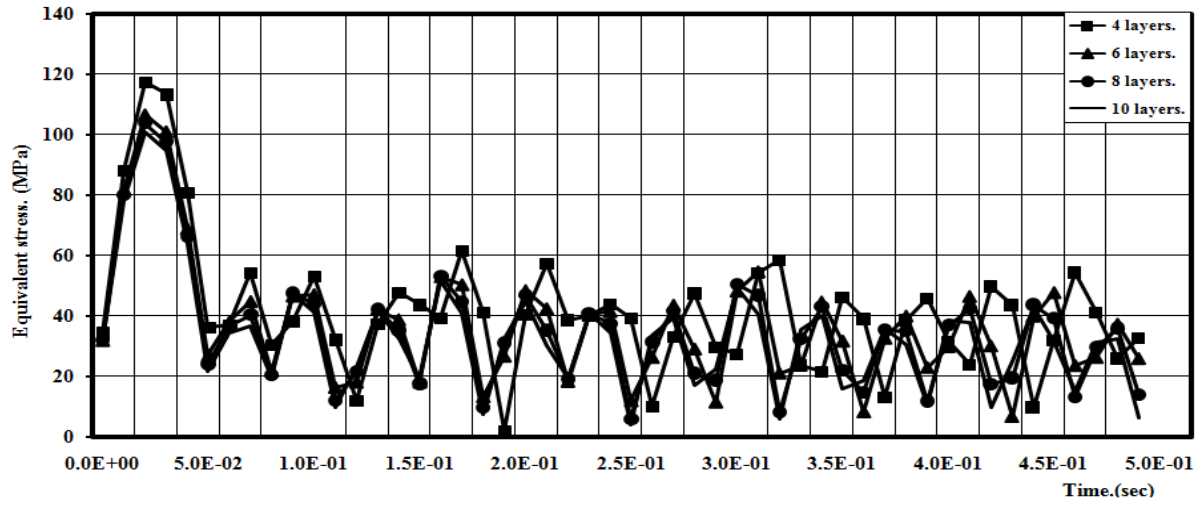

Fig. 21: Time-stress response for equivalent stress for angle-ply $45^{0}$ laminates of fixed supported shells

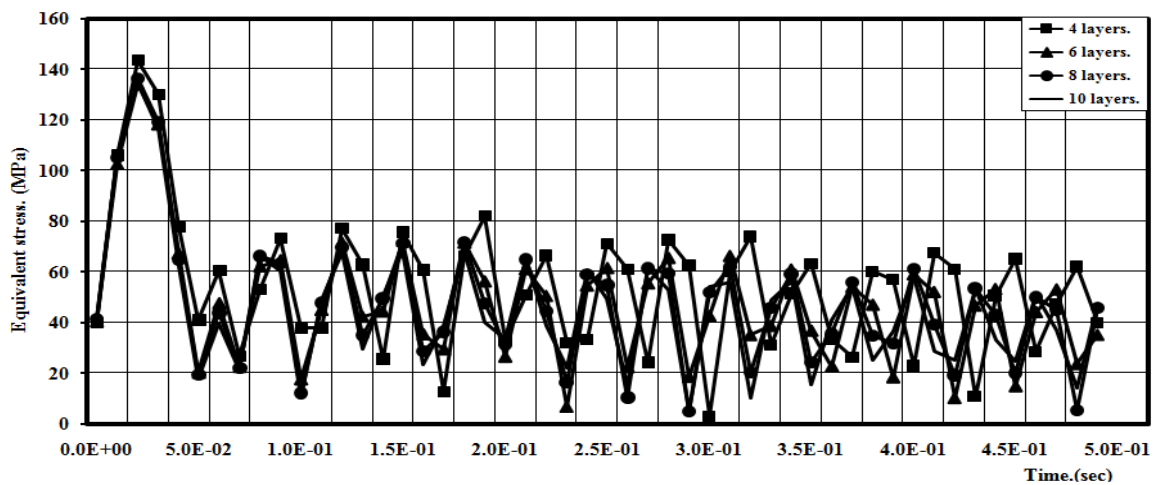

Fig. 22: Time-stress response for equivalent stress for angle-ply $60^{\circ}$ laminates of fixed supported shells

From the previous figures, it is noticed that:

For cross-ply laminates, as the number of layers increases the total displacement decreases for different boundary conditions of shells. The total displacement has the biggest values when the number of layers is four at time $=0.06 \mathrm{sec}$ for simply supported shells and time $=0.05 \mathrm{sec}$ for fixed supported shells. As the number of layers increases the equivalent stresses decrease for simply supported shells and the equivalent stresses have the biggest values when the number of layers is four at time $=0.06 \mathrm{sec}$. For fixed supported shells, as the number of layers increases the equivalent stresses increase until time is equal $0.03 \mathrm{sec}$ and the equivalent stresses have the biggest value when the number of layers is ten. After time is equal $0.03 \mathrm{sec}$, as the number of layers increases the equivalent stresses decrease and it have the biggest values when the number of layers is four.

For $30^{\circ}, 45^{\circ}$ and $60^{\circ}$ angle-ply laminates, the total displacement decreases as the number of layers increases for different boundary conditions of shells and the total displacement has the biggest values when the number of layers is four at time $=0.05 \mathrm{sec}$ for simply supported shells and time $=0.04 \mathrm{sec}$ for fixed supported shells. As the number of layers increases the equivalent stresses decrease for different boundary conditions of shells and the equivalent stresses have the biggest values when the number of layers is four at time $=0.04 \mathrm{sec}$ for simply supported shells and time $=0.03 \mathrm{sec}$ for fixed supported shells. 


\section{3-2 Effect of orientation angle}

Fig. 23. to Fig. 26. present time-displacement response for total displacement for cross and angle-ply laminates of simply supported shells for four, six, eight and ten layers respectively. Fig. 27. to Fig. 30. present time-stress response for equivalent stress for cross and angle-ply laminates of simply supported shells for four, six, eight and ten layers respectively.

Fig. 31. to Fig. 34. present time-displacement response for total displacement for cross and angle-ply laminates of fixed supported shells for four, six, eight and ten layers respectively. Fig. 35. to Fig. 38. present time-stress response for equivalent stress for cross and angle-ply laminates of fixed supported shells for four, six, eight and ten layers respectively.

From the previous figures, it is noticed that:

In generally, for different boundary conditions of shells, as the orientation angle increases the total displacement decreases and it has the least values when the orientation angle is $60^{\circ}$. The cross-ply laminates have total displacement higher than that for angle-ply $30^{\circ}, 45^{\circ}$ and $60^{\circ}$ laminates with number of layers four and six for simply supported shells and it have total displacement higher than that for angle-ply $45^{\circ}$ and $60^{\circ}$ laminates with number of layers eight and ten. For fixed supported shells, The cross-ply laminates have total displacement higher than that for angle-ply $30^{\circ}, 45^{\circ}$ and $60^{\circ}$ laminates with number of layers four and it have total displacement higher than that for angle-ply $45^{\circ}$ and $60^{\circ}$ laminates with number of layers six, eight and ten.

As the orientation angle increases the equivalent stresses decrease for simply supported shells and the equivalent stresses have the biggest values when the orientation angle is $30^{\circ}$ and it have the smallest values when the orientation angle is $45^{\circ}$ with all number of layers. The cross-ply laminates have equivalent stresses small than that for angle-ply $30^{\circ}, 45^{\circ}$ and $60^{\circ}$ laminates with all number of layers for simply supported shells. As the orientation angle increases the equivalent stresses increase for fixed supported shells and the equivalent stresses have the biggest values when the orientation angle is $60^{\circ}$ with all number of layers. The cross-ply laminates have equivalent stresses higher than that for angle-ply $30^{\circ}$ and $45^{\circ}$ laminates with all number of layers for fixed supported shells.

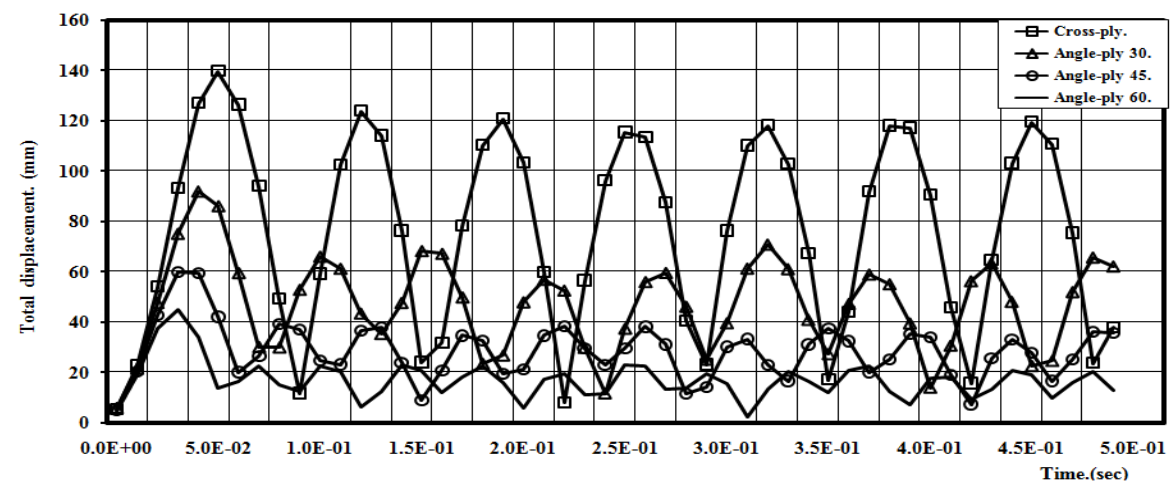

Fig. 23: Time-displacement response for total displacement for four layers cross and angle-ply laminates of simply supported shells

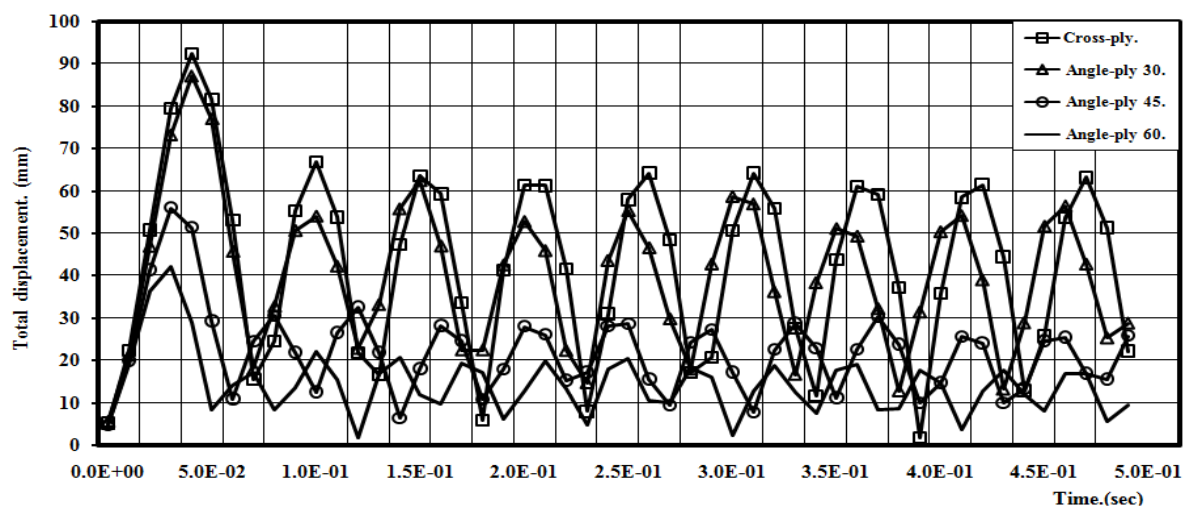

Fig. 24: Time-displacement response for total displacement for six layers cross and angle-ply laminates of simply supported shells 


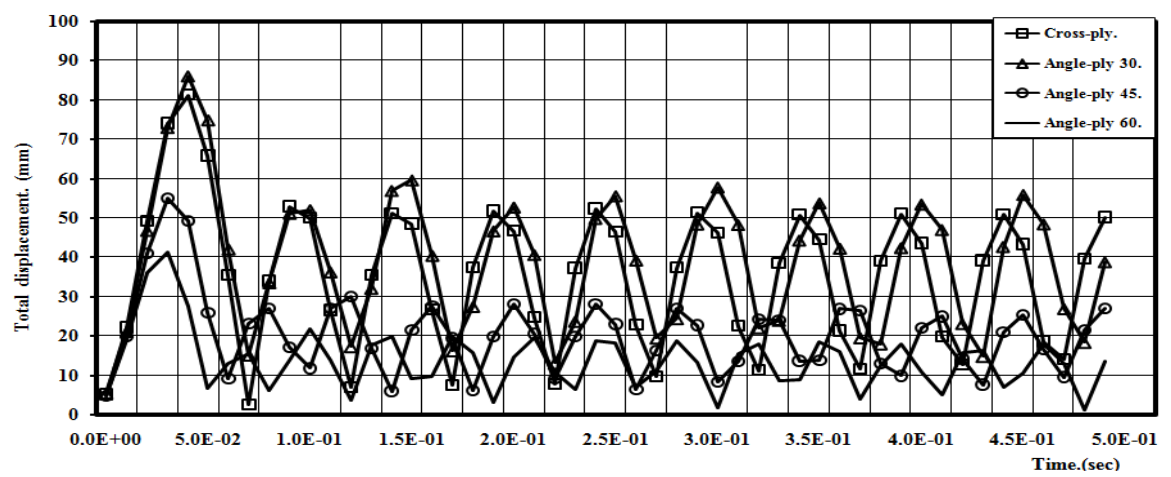

Fig. 25: Time-displacement response for total displacement for eight layers cross and angle-ply laminates of simply supported shells

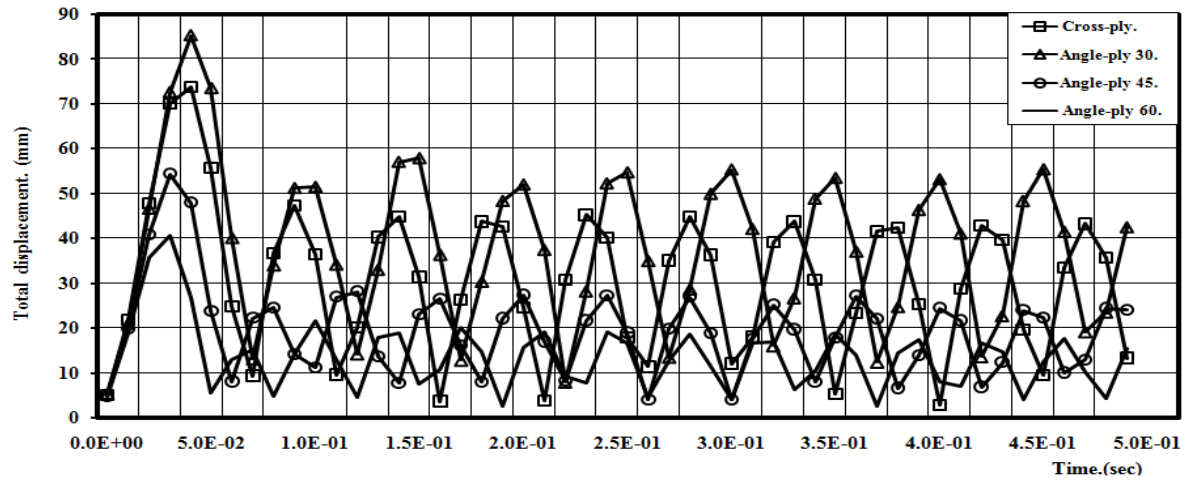

Fig. 26: Time-displacement response for total displacement for ten cross and angle-ply laminates of simply supported shells

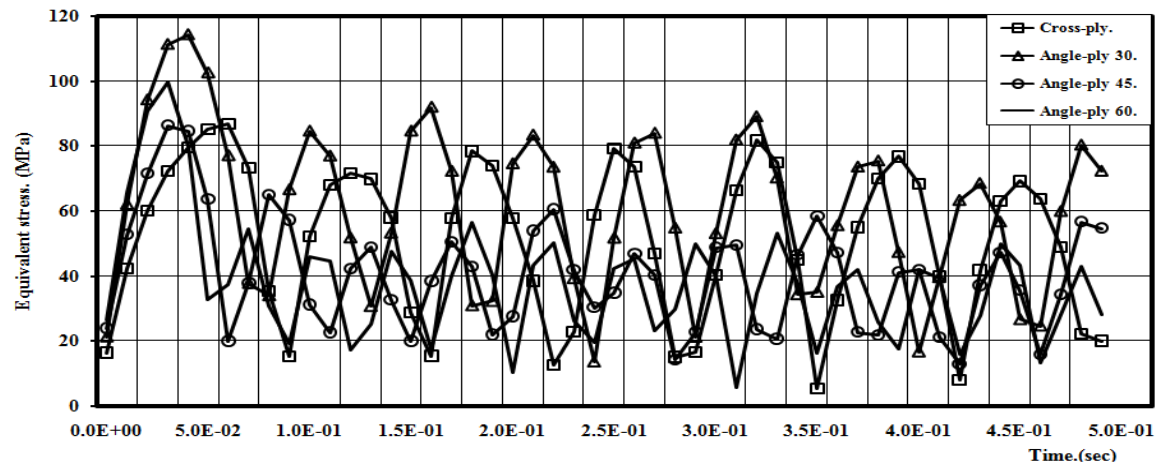

Fig. 27: Time-stress response for equivalent stress for four layers cross and angle-ply laminates of simply supported shells

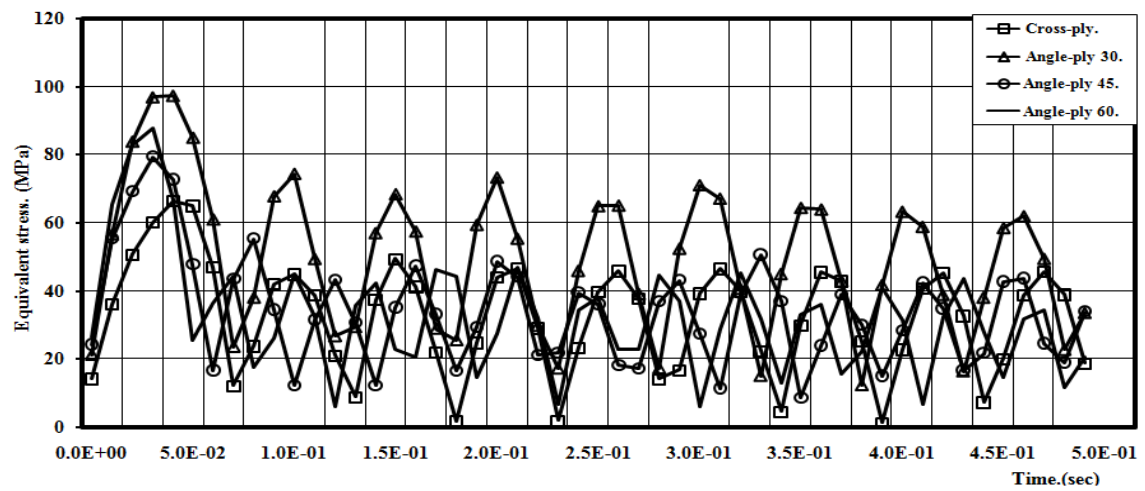

Fig. 28: Time-stress response for equivalent stress for six layers cross and angle-ply laminates of simply supported shells 


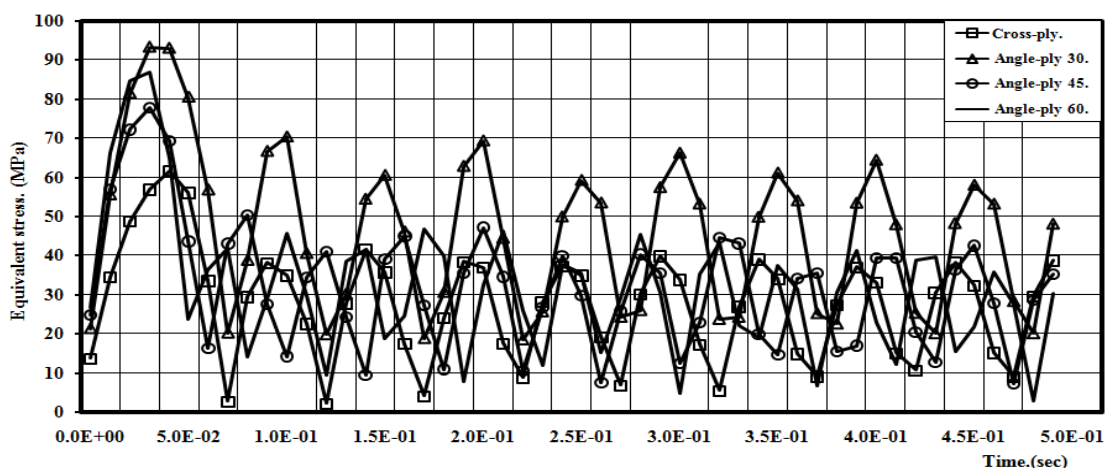

Fig. 29: Time-stress response for equivalent stress for eight layers cross and angle-ply laminates of simply supported shells

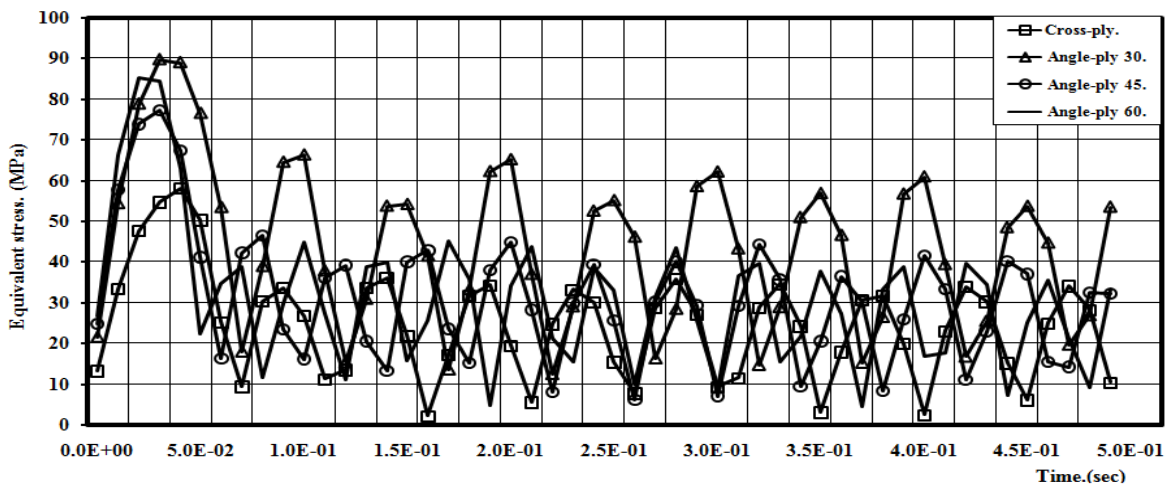

Fig. 30: Time-stress response for equivalent stress for ten layers cross and angle-ply laminates of simply supported shells

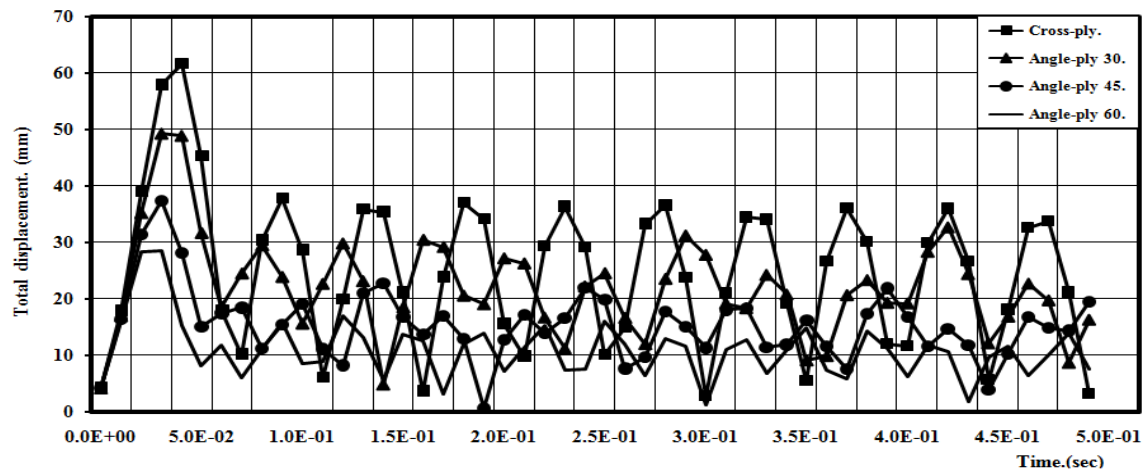

Fig. 31: Time-displacement response for total displacement for four layers cross and angle-ply laminates of fixed supported shells

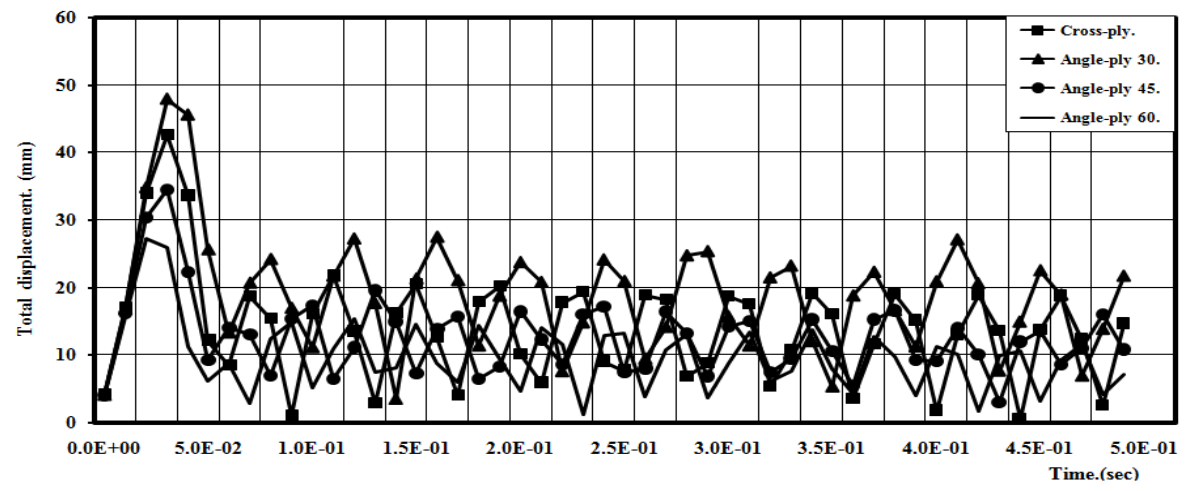

Fig. 32: Time-displacement response for total displacement for six layers cross and angle-ply laminates of fixed supported shells 


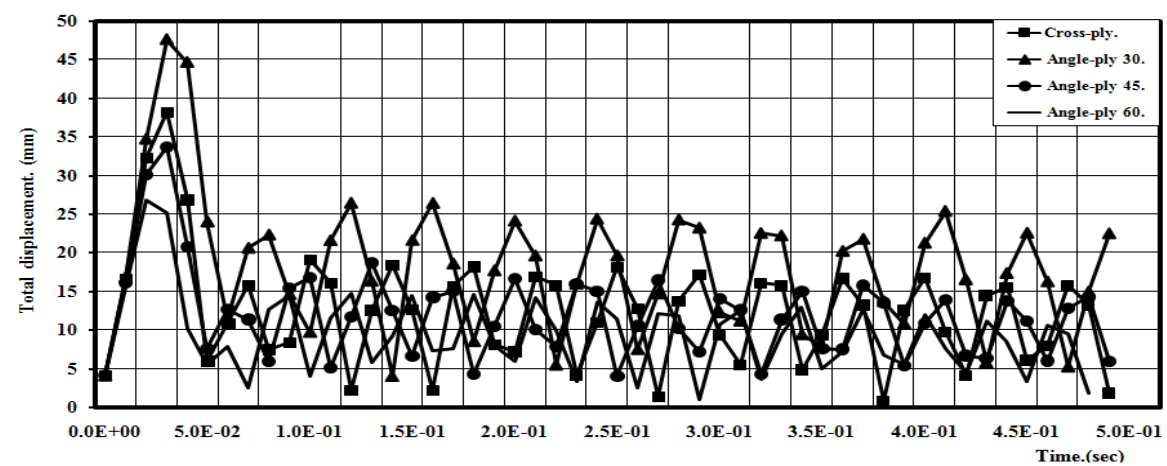

Fig. 33: Time-displacement response for total displacement for eight layers cross and angle-ply laminates of fixed supported shells

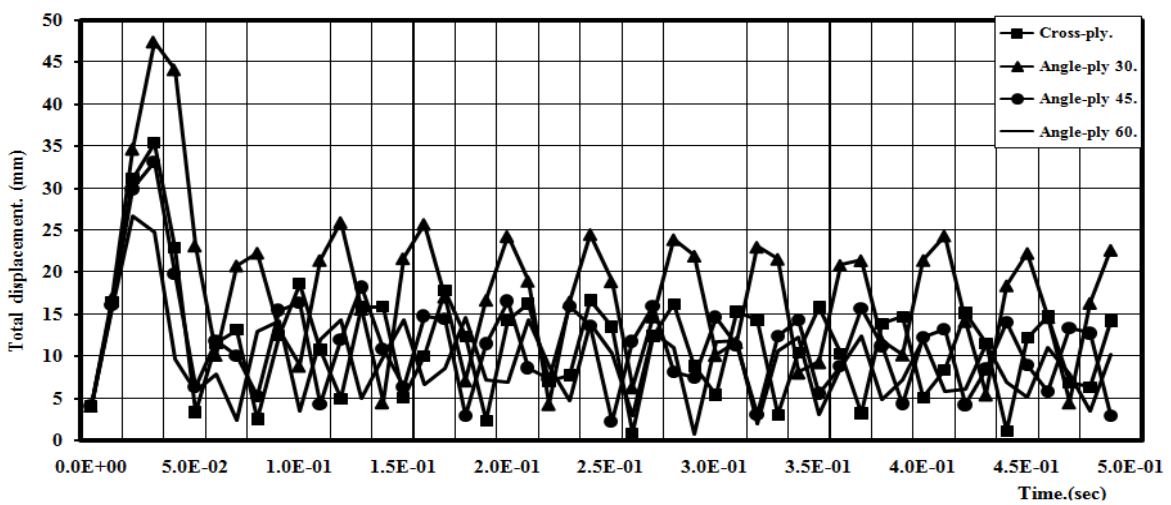

Fig. 34: Time-displacement response for total displacement for ten layers cross and angle-ply laminates of fixed supported shells

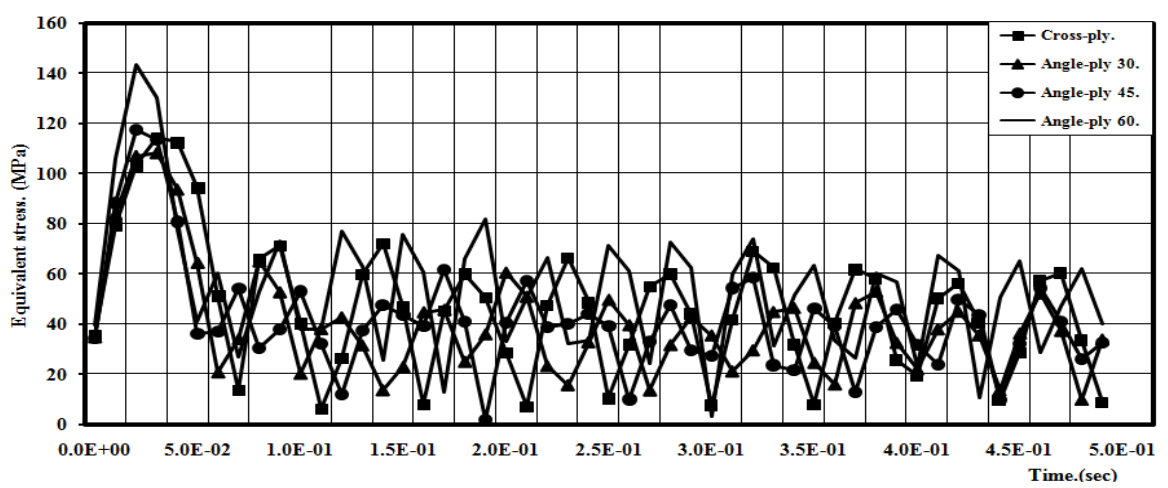

Fig. 35: Time-stress response for equivalent stress for four layers cross and angle-ply laminates of fixed supported shells

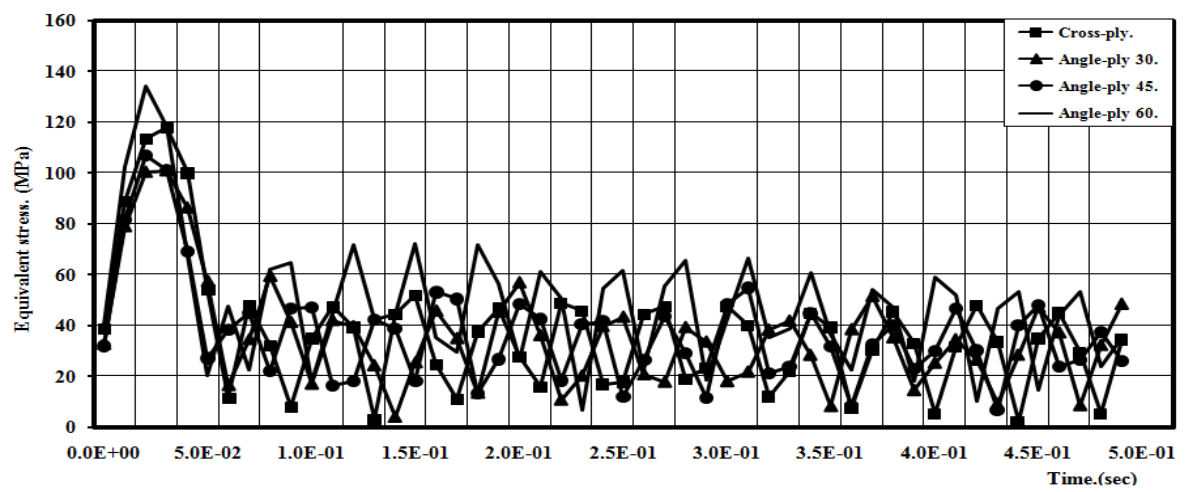

Fig. 36: Time-stress response for equivalent stress for six layers cross and angle-ply laminates of fixed supported shells 


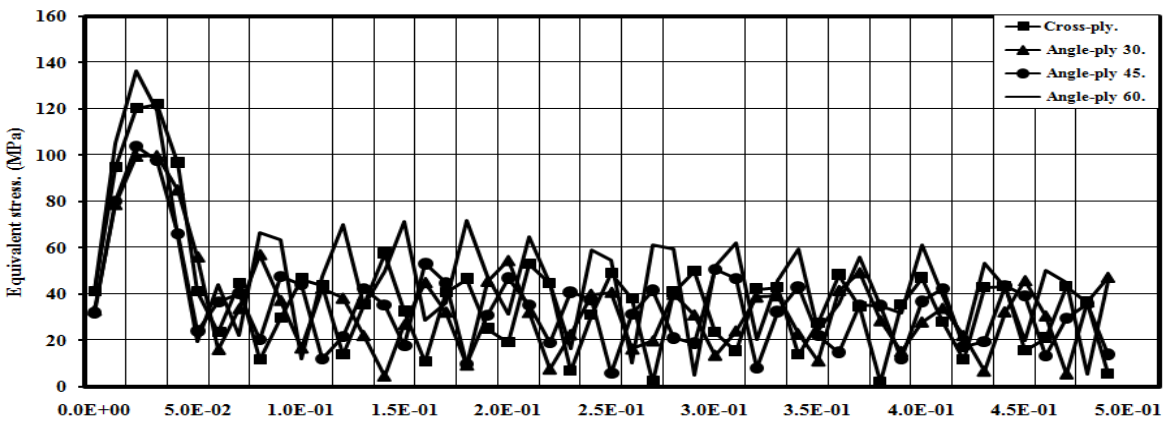

Fig. 37: Time-stress response for equivalent stress for eight layers cross and angle-ply laminates of fixed supported shells

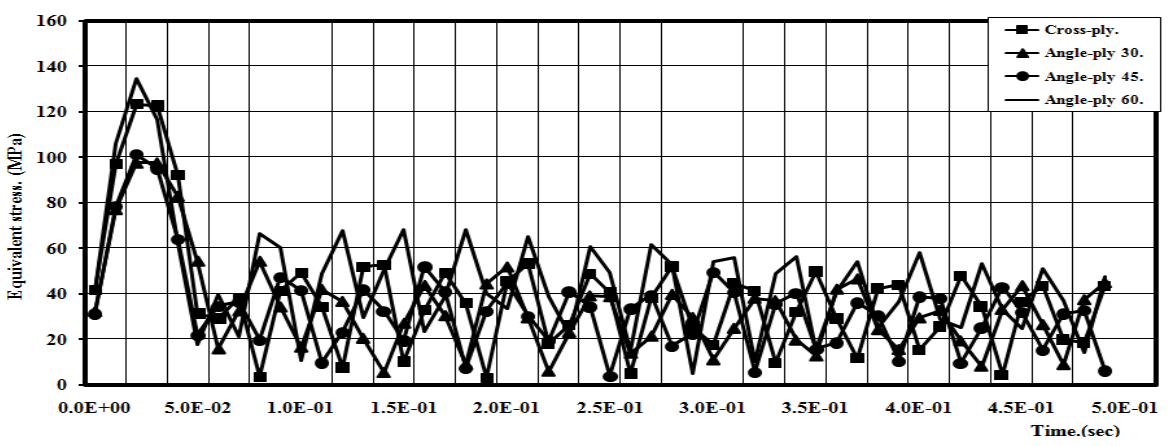

Fig. 38: Time-stress response for equivalent stress for ten layers cross and angle-ply laminates of fixed supported shells

\section{3-3 Effect of boundary conditions}

Fig. 39. presents comparison of number of layers on the total displacement for simply and fixed supported cross-ply laminates shells at times $0.04,0.05$ and $0.06 \mathrm{sec}$. Fig. 40. presents comparison of number of layers on the equivalent stresses for simply and fixed cross-ply laminates shells at times $0.03,0.04$ and 0.05 sec.

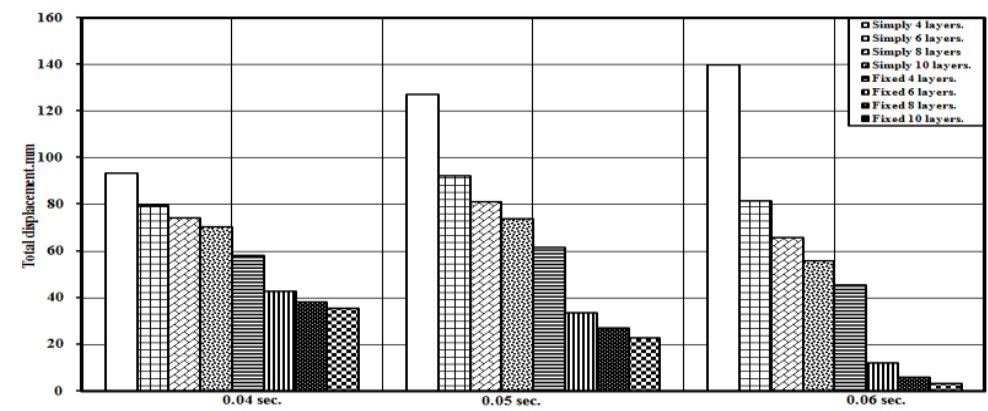

Fig. 39: Comparison of number of layers on the total displacement for simply and fixed cross-ply laminates shells at times $0.04,0.05$ and $0.06 \mathrm{sec}$

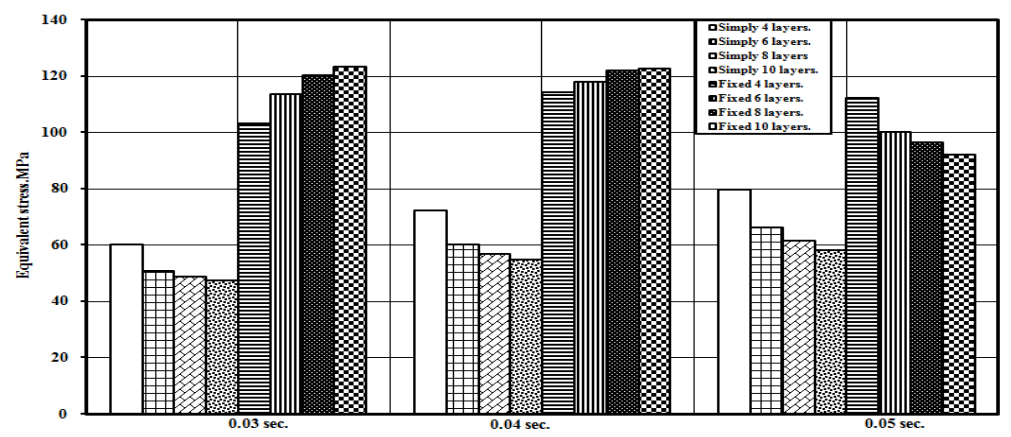

Fig. 40: Comparison of number of layers on the equivalent stresses for simply and fixed cross-ply laminates shells at times $0.03,0.04$ and $0.05 \mathrm{sec}$ 
From the previous figures, it is noticed that:

For cross-ply laminates shells, The total displacement for shells with fixed supported is less than that for shells with simply supported with the increase of the number of layers. The equivalent stresses for shells with fixed supported are higher than that for shells with simply supported with the increase of the number of layers.

Fig. 41. presents comparison of number of layers on the total displacement for simply and fixed angle-ply laminates shells at time $0.04 \mathrm{sec}$. Fig. 42. presents comparison of number of layers on the equivalent stresses for simply and fixed angle-ply laminates shells at time $0.03 \mathrm{sec}$.

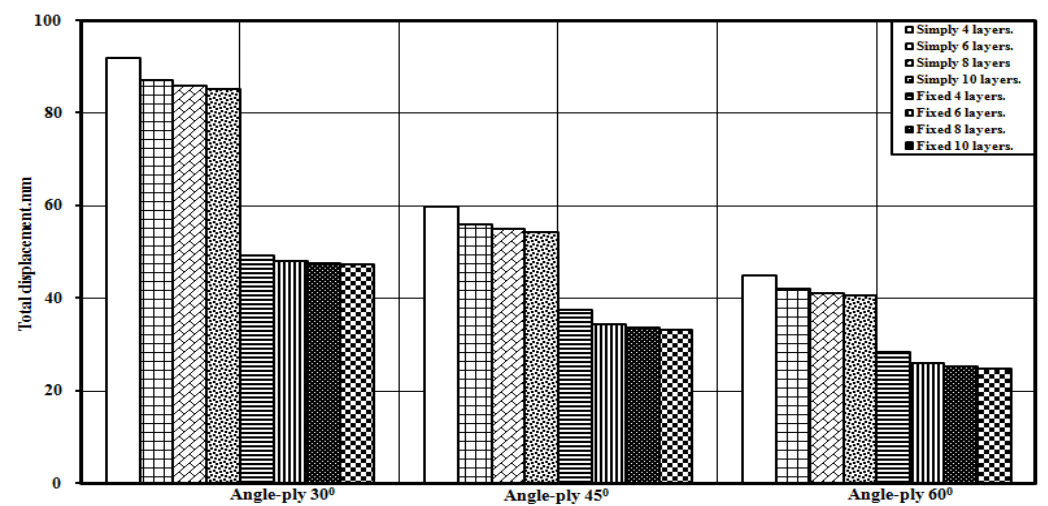

Fig. 41: Comparison of number of layers on the total displacement for simply and fixed angle-ply laminates shell at time $0.04 \mathrm{sec}$

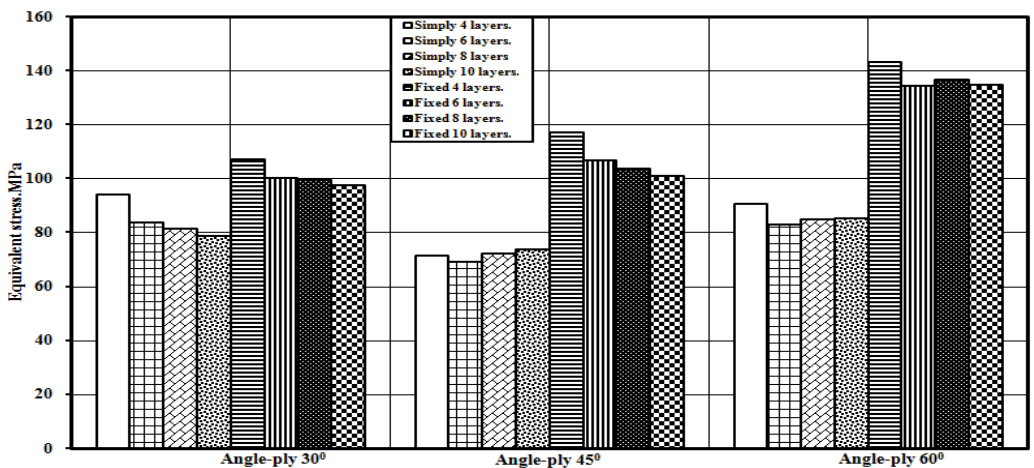

Fig. 42: Comparison of number of layers on the equivalent stresses for simply and fixed angle-ply laminates shell at time $0.03 \mathrm{sec}$

From the previous figures, it is noticed that:

For angle-ply laminates shells, The total displacement for shells with fixed supported is less than that for shells with simply supported with the increase of the orientation angle for all number of layers. The equivalent stresses for shells with fixed supported are higher than that for shells with simply supported with the increase of the orientation angle for all number of layers.

\section{Conclusions}

In this paper, the transient dynamic analysis of laminated composite shells has been done to study the effect of number of layers, orientation angle and boundary conditions on the dynamic response of laminated composite shells subjected to impulsive loads. From the results reported herein, the following conclusions are obtained:

1- Number of layers, orientation angle and boundary conditions have important effects on dynamic response of laminated composite shells subjected to impulsive loads which should be considered in design of laminated composite shells.

2- For cross and angle-ply laminates, as the number of layers increases the total displacement and the equivalent stresses decrease for different boundary conditions of shells and it have the biggest values when the number of layers is four.

3- As the orientation angle increases the total displacement decreases for different boundary conditions of shells with increasing the number of layers.

4- As the orientation angle increases the equivalent stresses decrease for simply supported shells and it increase for fixed supported shells with increasing the number of layers. 
5- The total displacement for shells with fixed supported is less than that for shells with simply supported with the increase of the number of layers for cross and angle-ply laminates and the equivalent stresses for shells with fixed supported are higher than that for shells with simply supported with the increase of the number of layers for cross and angle-ply laminates.

\section{References}

[1] S. K. Sahu and P. K. Datta ,Dynamic stability of laminated composite curved panels with cutouts, Journal of Engineering Mechanics, Vol. 129, No. 11, November 2003.

[2] A. Karmakara and K. Kishimotob ,Transient dynamic response of delaminated composite rotating shallow shells subjected to impact, Shock and Vibration $13,2006,619-628$.

[3] A. L. Poore, A. Barut and E. Madenci ,Free vibration of laminated cylindrical shells with a circular cutout, Journal of Sound and Vibration $312,2008,55-73$.

[4] S. Kumar ,Analysis of impact response and damage in laminated composite shell involving large deformation and material degradation, Journal of Mechanics of Materials and Structures, Vol. 3, No. 9, 2008.

[5] F. S. Almeida and A. M. Awruch, ,Corotational nonlinear dynamic analysis of laminated composite shell structures, 11th PanAmerican Congress of Applied Mechanics, January 2010, Brazil.

[6] F. Firouzabadi1, A. B. Ayob, M. Moradpour, R. Heidarpour and N. Deirram. , Dynamic response of laminated composite cylindrical shell subjected to pure impact, Applied Mechanics and Materials, Vols. (229-231), 2012, pp 2577-2581.

[7] A. Kumar, A. Chakrabarti and P. Bhargava,Vibration of laminated composite cylindrical shells with cutouts using higher order theory, International Journal of Scientific \& Engineering Research Volume 4, (Issue 5), May 2013.

[8] V. Chitra and R.S. Priyadarsini ,Dynamic buckling of composite cylindrical shells subjected to axial impulse, International Journal of Scientific \& Engineering Research Volume 4 ( Issue 5), May-2013.

[9] R. R. Dasa, A. Chakrabortya, A. Guchhaita and A. Singlaa ,Dynamic response of laminated FRP composite made cracked spherical shells subjected to free vibration, Procedia Materials Science 6, 2014, 1580-1587.

[10] S. M. Saji and Prabha ,Free vibration analysis of laminated composite shallow shells, International Journal of Research in Engineering \& Technology, Vol. 2( Issue 9), Sep 2014, 51-58.

[11] C. Lakshmi and K.K. Smitha ,Free vibration analysis of laminated composite cylindrical panel using ANSYS, International Journal of Innovative Research in Science, Engineering and Technology,Vol.4 (Special Issue 12), September 2015.

[12] K. S. Ram and T. V. Jyothi ,Transient response of laminated composite spherical shell cap, IJRET: International Journal of Research in Engineering and Technology Volume: 04 (Special Issue:13), Dec. 2015. 